\title{
Expression of Cox-2 and Bcl-2 in Paget's Disease of the Breast
}

\author{
Arsenal Sezgin Alikanoglu ${ }^{1}$, Mustafa Yldırım² ${ }^{2}$ Dinc Suren $^{2}$, Birsel Tutus $^{3}$, Vildan \\ $\mathrm{Kaya}^{4}$, Cumhur Selcuk Topal ${ }^{5}$, Sevinc Keser ${ }^{6}$, Ayse Nimet Karadayi ${ }^{6}$, Fatma \\ Nilgun Kapucuoglu ${ }^{7}$, Sebnem Ayva ${ }^{8}$, Seyda Gunduz**
}

\begin{abstract}
Background: Paget's disease (PD) is a rare form of intraepithelial adenocarcinoma that involves breast and extramammarian tissues. It is often associated with ductal carcinoma in situ and/or invasive ductal cancer. Molecular pathways that play a role in development of Paget's disease are stil unclear. Expression patterns of Cox-2 and bcl-2 were therefore assessed. Materials and Methods: Patients with a histopathological diagnosis of Paget's disease were included in this study. Patient files were analysed retrospectively. $\underline{\text { Results: Invasive cancer }}$ was diagnosed in $35(76.1 \%)$ of the patients, $7(15.2 \%)$ had ductal carcinoma in situ and $4(8.7 \%)$ patients had no associated neoplasm. Twenty four $(52.2 \%)$ patients showed COX-2 expression in Paget cells whereas no expression was seen in $22(47.8 \%)$ patients. No relation was found between COX-2 expression and the lesion underlying Paget's disease ( $p=0.518)$. Bcl-2 expression in Paget cells was found positive in $12(26.1 \%)$ and negative in 27 $(58,7 \%)$ cases. There was no relation between Bcl-2 expression and the lesion accompanying Paget's disease $(p=0.412)$. No relation was observed between $\mathrm{COX}-2$ expression and $\mathrm{Bcl}-2$ expression $(\mathrm{p}=0.389)$. Conclusions: In breast cancer, COX-2 expression is associated with poor prognostic factors. As COX-2 expression increases the tendency to metastasize also increases. In our study we found a significantly high COX-2 expression in Paget's disease of the breast. We suggest that COX-2 expression and inflammatory processes may play a role in pathogenesis of the Paget's disease of the breast.
\end{abstract}

Keywords: Paget's disease - breast cancer - COX-2 - Bcl-2 - inflammation

Asian Pac J Cancer Prev, 16 (3), 1041-1045

\section{Introduction}

Paget's disease (PD) is a rare form of intraepithelial adenocarcinoma that involves breast and extramammarian tissues. PD of the breast, a disorder of the nipple-areola complex first described by Sir James Paget in 1874 accounts for 1-3\% of all breast cancers (Paget, 1874). It is often associated with ductal carcinoma in situ and/ or invasive ductal cancer. Clinical differential diagnosis of Paget's disease of the breast include atopic or contact dermatitis of the nipple, chronic eczema, psoriasis and inflammatory changes such as chronic nipple discharge and sphylitic chancre (Karakas, 2011).

There are two theories on the hypothesis of the nature and origin of PD: the epidermotropic theory and in-situ malignant transformation theory. The "epidermotrophic" theory postulates that Paget's cells originate from the cancer cells of the ductus that have migrated along the basal membrane of the epidermis of the nipple (Muir, 1939; Ashikari et al., 1970). The similiarity of the immunohistochemical staining of the Paget's cells and the underlying carcinoma supports this theory (Cohen et al., 1993). The "in situ malignant transformation" theory regards the Paget's cells as malignant keratinocytes appearing in situ and PD as an in situ carcinoma, independent of any underlying pre-cancerous or cancerous condition. Ultrastructural studies demonstrating microvilli and desmosomal attachments between the keratinocytes and Paget's cells suppor

this theory (Sagami, 1963; Jahn et al., 1995). In recent years, it has been suggested that human epidermal growth factor receptor 2 (HER2) and vimentin filaments may be related to the pathogenesis of Paget's disease (Hanna et al., 2003).

Prostaglandins, the potent inflammatory mediators, play a significant role in cell proliferation and apoptosis. COX is the limiting enzyme in the synthesis of prostaglandins from arachidonic acid. This enzyme exists in two isoforms, COX-1 and COX-2 (Smith et al., 2000). The expression of COX-2 is lower in normal tissues,

${ }^{1}$ Department of Pathology, ${ }^{9}$ Department of Medical Oncology, Antalya Education and Research Hospital, ${ }^{3}$ Department of Pathology, Ministry of Health Finike Regional Goverment Hospital, ${ }^{8}$ Department of Pathology, Baskent University, Antalya, ${ }^{3}$ Department of Medical Oncology, Ministry of Health Batman Regional Goverment Hospital, Batman, ${ }^{4}$ Department of Radiation Oncology, ${ }^{7}$ Department of Pathology, Suleyman Demirel University, Isparta, ${ }^{5}$ Department of Pathology, Umraniye Education and Research Hospital, ${ }^{6}$ Department of Pathology, Kartal Education and Research Hospital, Istanbul, Turkey *For correspondence:drsgunduz@ gmail.com 
but it increases in neoplastic tissues and inflammatory conditions. The role of COX-2 expression was shown in different malignancies (Masferrer et al., 2000; O'Byrne et al., 2001).

Bcl-2 gene was identified first in patients with B cell follicular lymphoma with $\mathrm{t}(14 ; 18)$ translocation, however its expression is not related to this translocation. Bcl-2 increases the lifespan of a cell by inhibiting apoptosis, but due to the longer lifespan the possibility the cell come across mutagenic factors increases. Bcl-2 is known as an oncogene but different from the other oncogenes it does not increase the cell proliferation and therefore cells which have a high proliferation index because of DNA damage gains an advantage of survival. Although bcl-2 plays a role in carcinogenesis it is associated with a less agressive behaviour in many types of cancer (Kirkina et al., 2004; Alikanoglu et al., 2013).

Molecular pathways that play a role in development of Paget's disease are stil unclear. Expression patterns of Cox-2 and bcl-2 in Paget's disease of the breast are searched in this study.

\section{Materials and Methods}

\section{Patients}

Patients with a histopathologically diagnosed Paget's disease of the breast in Antalya Education and Research Hospital, Kartal Education and Research Hospital, , Umraniye Education and Research Hospital, Suleyman Demirel University Medical Faculty Hospital and Başkent University Medical Faculty Hospital, between 1996-2012 were included in this study. Patient files were analysed retrospectively and data including age, gender, underlying breast disease and hormone receptor status were retrieved.

\section{Immunohistochemistry}

Tumor samples obtained after biopsy or surgery were immediately fixed in $10 \%$ formaldehyde and then embedded in paraffin. Afterwards, $4 \mu \mathrm{m}$-thick histological sections were obtained from paraffin blocks and were initially stained with haematoxylin-eosin for initial assessment.

The histological sections were de-paraffinized and incubated at $60^{\circ} \mathrm{C}$ for one h. Afterwards, they were kept in xylene for $10 \mathrm{~min}$ and in $100 \%$ alcohol for $5 \mathrm{~min}$ and then washed with distilled water. Slides were kept in solution buffered with $10 \%$ citrate solution in microwave oven at maximum power ( 800 watts) for $15 \mathrm{~min}$. Then, the power was decreased by half and slides were kept in the microwave oven for another $20 \mathrm{~min}$. Slides taken out of the microwave oven were kept at room temperature for $20 \mathrm{~min}$. Endogenous peroxidase activity was blocked by keeping them in $3 \%$ hydrogen peroxide for $20 \mathrm{~min}$. Then, the slides, washed with distilled water, were treated with phosphate buffer saline (PBS) for $5 \mathrm{~min} \times 3$ times and with protein blocking agent (Novocastra Protein Block, Newcastle, UK). After being kept in primary antibody bcl- 2 for (clone100/D5, 1:50, Thermo Scientific, Fremont, ABD) and Cox-2 for (clone 4H12, 1:30, DBS, Pleasanton CA) for $30 \mathrm{~min}$, they were taken into PBS and washed for $5 \mathrm{~min}$. Then, they were treated with biotinylated secondary antibody (vector Laboratories,Burlingham,CA) for 20 min, washed in PBS for $5 \mathrm{~min}$ and kept together with peroxidase conjugate antibody (Novocastra Peroxidase Block, Newcastle, UK) for $20 \mathrm{~min}$. Then, they were washed in PBS for 5 min and kept in chromogen (DAB) for $5 \mathrm{~min}$. Slides washed under tap water were adversely stained with haematoxylin. Then, they were dehydrated, dried and covered with mounting medium. Then, slides were inspected under Nikon Eclipse 80 (NIKON, USA) microscope.

\section{Immunohistochemistry scoring}

Slides were evaluated by two pathologists (DS, ASA) who were blinded of the patients' clinical characteristics. Cytoplasmic/membranous staining of Bcl2 and cytoplasmic staining of COX -2 in $\geq 10 \%$ of the Paget cells was considered as positive expression while staining $\leq 10 \%$ was accepted as negative expression. Samples with high expression rate were examined under low power whereas samples with a low rate or no expression were evaluated under high power of view.

\section{Statistical Analysis}

Statistical analyses were performed using the SPSS software version 15 (SPSS Inc, Chicago, IL). Compatibility of the variables with normal distrubition were analysed by visual (histiogram and possibility graphics) and analytical methods (Kolmogorov-Smirnov/ Shapiro-Wilk tests). In Kolmogorov-Simirnov test, a p value of $>0,005$ was accepted as normal distrubition. Differences between groups were assessed by using Chisquare and Mann- Whitney U test. A p value of $<0.05$ was considered statistically significant.

\section{Results}

A total of 46 patients $45(97.8 \%)$ of whom were female were included in this study. One of the patients $(2.2 \%)$ were male. The mean patient age was $54.7 \pm 13.1$ (range 22-89). Breast involvement was unilateral in all of the patients. Thirty-eight $(82.6 \%)$ of the patients had modified radical mastectomy, $2(4.3 \%)$ had lumpectomy and a core biopsy was performed in $6(13 \%)$ of the patients.

In $26(56.5 \%)$ of the patients left breast and in 20 (43.5\%) of them right breast was involved, Invasive cancer was diagnosed in $35(76.1 \%)$ of the patients, 7 (15.2\%) patients had ductal carcinoma in situ and $4(8.7 \%)$ patients had no associated neoplasm.

Estrogen and progesterone receptor was found positive in $38.5 \%$ and $33.3 \%$ of patients with invasive cancer, respectively. In $41 \%$ of the patients diagnosed with invasive cancer, a strong immunreactivity (score $3+$ ) of Her-2 was established. Histologic grade of the tumour was determined as 2 in $18(58.1 \%)$ and 3 in $13(41.9 \%)$ of the 31 patients in which histologic grade of the invasive cancer could be assesed.

Estrogen receptor was found positive in $32.6 \%$, progesterone receptor was found in $26.1 \%$ of patients with ductal carcinoma in situ. The rate of score $3+$ Her- 2 expression in patients with ductal carcinoma in situ was found as $37 \%$. 

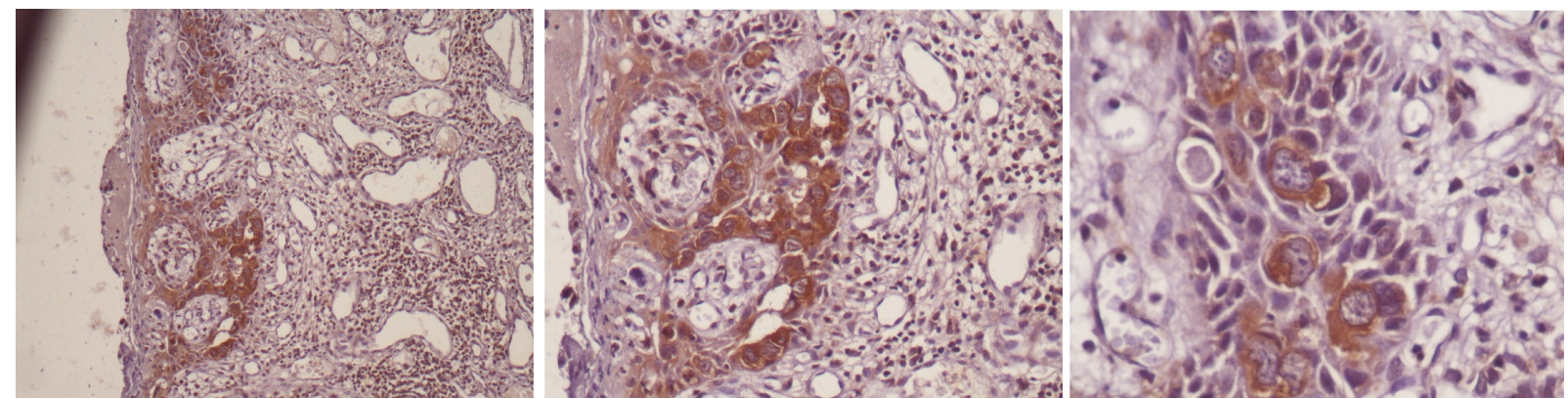

Figure 1. Cox-2 Positivity in Paget Cells, IHC, X100, X200, X400
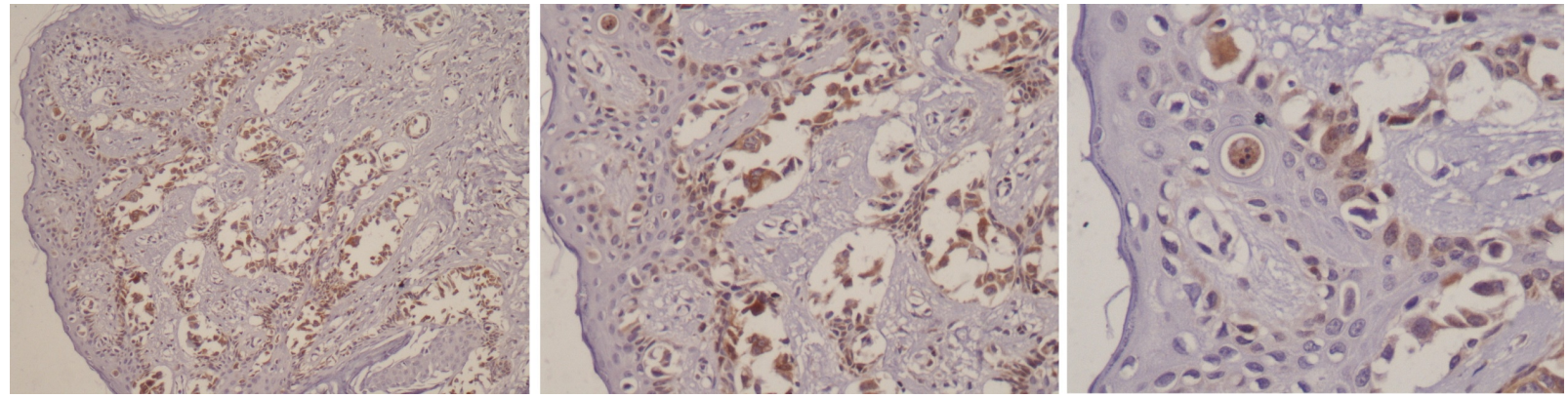

Figure 2. Bcl-2 Positvity in Paget Cells IHC, X100, X200, X400

Twenty four (52.2\%) patients showed COX-2 expression in Paget cells whereas no expression was seen in $22(47.8 \%)$ patients. No relation was found between COX-2 expression and the lesion underlying Paget's disease $(\mathrm{p}=0.518)$ (Figure 1). Bcl-2 expression in Paget cells was found positive in $12(26.1 \%)$ and negative in $27(58,7 \%)$ cases (Figure 2). Bcl-2 expression was not assessed in $7(15.2 \%)$ cases because of tissue inadequacy for immunohistochemical staining. There was no relation between $\mathrm{Bcl}-2$ expression and the lesion accompanying Paget's disease $(\mathrm{p}=0.412)$. No relation was observed between COX-2 expression and Bcl-2 expression $(\mathrm{p}=0.389)$.

\section{Discussion}

The results of our study demonstrated a significantly high COX-2 expression in Paget's disease of the breast.

In our study, of the 46 patients with Paget's disease of the breast, invasive cancer was diagnosed in $35(76.1 \%)$ of the patients, $7(15.2 \%)$ patients had ductal carcinoma in situ and 4 (\%8.7) patients had no associated neoplasm.

The presence of PD in patients with breast cancer had an overall 5-year survival of $81.2 \%$ vs $93.8 \%$ in patients without PD. The presence of PD may independently confer a poorer prognosis, as suggested by the adjusted HR (2.26) for the overall 5-year survival (Ortiz-Pagan et al., 2011). This poorer survival may be associated with biological markers. Few of these tumors expressed Bcl-2 or ER and $\mathrm{PR}$, which are generally associated with better prognosis in breast cancer (Chen et al., 2006; Rostamizadeh et al., 2013).

In a study of Horn et. al analysing COX-2 and Her-2 expression in Paget's disease of the vulva and the breast; of the 11 patients with Paget's disease of the breast, $6(54.5 \%)$ were associated with ductal carcinoma in situ (DCIS) and
$5(45.5 \%)$ with invasive cancer (three invasive ductal and two with invasive lobular carcinoma) (Horn et al,2006). Another report showed that the expression of neu protein in Paget's disease, of 23 patients with mammarian Paget's disease, $12(52.2 \%)$ patients had associated intraductal carcinoma and $6(26.1 \%)$ patients primary invasive ductal breast carcinoma whereas $5(21.7 \%)$ patients were observed to have mammarian Paget's diseae without underlying ductal breast carcinoma (Meissner et al., 1990).

In present study, $\mathrm{COX}-2$ and $\mathrm{Bcl}-2$ expression in Paget's disease of the breast was found as $52.2 \%$ and $26.1 \%$, respectively. Overexpression of COX-2 was shown in different types of solid tumours in several studies (Xiang et al., 2012; Davies et al., 2002). Half et al (2002) detected frequent expression of COX-2 in epithelial cells of human breast adenocarcinomas and adjacent DCIS in their study.

COX-2 expression is known as a poor prognostic factor in breast cancer. Increase in expression of COX-2 is associated with metastasis (Costa et al., 2002; Denkert et al., 2003). Kim et al. (2012) found COX-2 expression positive in $62.3 \%$ of the triple-negative breast cancers in their sudy and suggested that COX-2 expression is a bad prognostic factor. A similiar expression rate was found in a study analysing the response to neoadjuvant therapy (Darb-Esfahani et al., 2009). In a recent study by Witton et al. (2004) COX2 expression was found in $21.2 \%$ of cases with breast cancer and it was associated with poor outcome in the subgroup of estrogen receptor negative breast cancers.

Horn et. al analysed COX-2 and Her-2 expression in Paget's disease of the vulva and the breast in their study and found that 10 out of 11 mammary (91\%) Paget's disease showed COX-2 overexpression. In our study, we found COX-2 expression rate as $52.2 \%$, lower than Horn et al (2008) found. One of the reasons for this difference may be the number of patients involved in the study. 
The reason of overexpression of COX-2 in cells of breast cancer is unclear. It is suggested that tumor supressor genes such as p53 and oncogenes such as Her-2 induce expression of COX-2 in malignant cells (Mohammad et al., 2006).

Various studies have discussed the possible role of COX-2 inhibitors in chemoprevention of breast cancer and shown that the combination of COX-2 inhibitor with standard cancer chemotherapeutic and / or radiation may provide additional treatment protocols in several human cancers, including breast cancer (Davies et al., 2002; Evans and Kargman, 2004).

Bcl-2 expression has been searched in various types of cancer and was established as a good prognostic factor in the majority of them. On the other hand there are studies suggesting that bcl-2 has no prognostic significance (Ihemelandu et al., 2009; El-Mageed et al., 2013). Different expressions of bcl-2 in normal ductus epithelium, intraductal carcinoma and invasive cancer have been demonstrated in studies. Zhang et al. (1997) found rate of bcl-2 expression as $96 \%$ in normal ductus epithelium, $79 \%$ in intraductal carcinoma and $45 \%$ in invasive cancer and also established that bcl-2 expression decreases in development of carcinoma from normal ductus epithelium (Zhang et al., 1997). Bcl-2 expression is found related with well differentiation and ER expression in breast cancer (Silvestrini et al., 1994; Hasnan Jaafar et al., 2012). Yu et al. (2010) found a positive correlation between bcl-2 and ER,PR expression in their study searching the expression differences between very young and the other patients with breast cancer, similiar to our results.

Rhee et al. (2008) demonstrated that bcl-2 expression was significantly lower in the more agressive triplenegative group of breast cancer than the non-triplenegative group. Tawfik et al. (2012) found that positivity of Bcl-2 was in correlation with more agressive tumour histology and longer overall survival in non-triplenegative group whereas bcl-2 positivity was found to be related with shorter survival in triple-negative group, interestingly.

In a study of Zheng et al. (2013) Paget disease with invasive breast cancer showed larger tumor size, more multifocal disease, lower ER and PR expression and higher HER2 overexpression than those in other invasive breast cancer $(\mathrm{p}<0.05)$. On the other hand, Lester et al (2009) suggested that carcinomas with non-mammarian Paget's disease nipple involvement differ from those with mammarian Paget's disease since they are more likely to be ER- and PR-positive, HER2-negative, and luminal A subtype. They found that mammarian Paget's diseaese is more likely to be associated with ER- and PR-negative ductal carcinoma in situ (DCIS). In our study ER, PR and Her-2 expression in invasive cancer was found as $38.5 \%$, $33.3 \%$, and $41 \%$; respectively. Histologic grade of the tumour was determined as 2 in $18(58.1 \%)$ and 3 in 13 $(41.9 \%)$ of the 31 patients in which histologic grade of the invasive cancer could be assesed.

In breast cancer, $\mathrm{COX}-2$ expression is associated with poor prognostic factors. As COX-2 expression increases the tendency to metastasize also increases. In our study we found a significantly high COX-2 expression in Paget's disease of the breast. We suggest that COX-2 expression and inflammatory processes may play a role in pathogenesis of the Paget's disease of the breast.

\section{References}

Alikanoğlu AS, Yıldırım M, Süren D, et al(2013). Bcl-2 and $\mathrm{Ki}-67$ expression in young women with breast cancer. J Clin Anal Med, 4, 386-9.

Ashikari R, Park K, Huvos AG, Urban JA (1970). Paget's disease of the breast. Cancer, 26, 680-5.

Chen CY, Sun LM, Anderson BO (2006). Paget disease of the breast: changing patterns of incidence, clinical presentation, and treatment in the US. Cancer, 107, 1448-58.

Cohen C, Guarner J, De Rose PB (1993). Mammary Paget's disease and associated carcinoma. An immunohistochemical study. Arch Pathol Lab Med, 117, 291-4.

Costa C, Soares R, Reis-Filho JS, et al (2002). Cyclo-oxygenase 2 expression is associated with angiogenesis and lymph node metastasis in human breast cancer. J Clin Pathol, 55, 429-34.

Darb-Esfahani S, Loibl S, Müller BM, et al (2009). Identification of biology-based breast cancer types with distinct predictive and prognostic features: role of steroid hormone and HER2 receptor expression in patients treated with neoadjuvant anthracycline/taxane-based chemotherapy. Breast Cancer Res, 11, 69.

Davies G, Martin LA, Sacks N, Dowsett M (2002). Cyclooxygenase -2 (COX-2), aromatase and breast cancer: a possible role for COX-2 inhibitors in breast cancer chemoprevention. Ann Oncol, 13, 669-78

Denkert C, Winzer KJ, Muller BM, et al (2003). Elevated expression of cyclooxygenase- 2 is a negative prognostic factor for disease free survival and overall survival in patients with breast carcinoma. Cancer, 97, 2978-87.

El-Mageed AA, Mohamed AES and Elesawy BH (2013) Different Prognostic Factors Correlate with Bcl-2 Expression among Triple Negative and Non-Triple Negative Breast Cancers. Asian Pac J Cancer Prev, 14, 1037-41.

Evans JF, Kargman SL (2004). Cancer and Cyclooxygenase -2 (COX-2) inhibition. Curr Pharm Des, 10, 627-34.

Hanna W, Alowami S, Malik A (2003). The role of HER-2/neu oncogene and vimentin filaments in the production of the Paget's phenotype. Breast J, 9, 485-90.

Half E, Tang XM, Gwyn K, et al (2002). Cyclooxygenase-2 expression in human breast cancers and adjacent ductal carcinoma in situ. Cancer Res, 15, 1676-81.

Horn LC, Purz S, Krumpe C, Bilek K (2008). COX-2 and Her-2/ neu are overexpressed in Paget's disease of the vulva and the breast: results of a preliminary study. Arch Gynecol Obstet, 277, 135-8.

Ihemelandu CU, Dewitty RL, Leffall LD, Suryanarayana SM, Frederick WA (2009). Clinical significance of p53 and bcl-2 protein coexpression phenotypes in molecular breast cancer subtypes of pre-menopausal and post-menopausal AfricanAmerican women. Am Surg, 75, 776-84.

Jaafar H, Abdullah S, Murtey MD, Idris FM (2012) Expression of Bax and Bcl-2 in tumour cells and blood vessels of breast cancer and their association with angiogenesis and hormonal receptors. Asian Pacific J Cancer Prev, 13, 3857-62

Jahn H, Osther PJ, Nielsen EH, Rasmussen G, Andersen J (1995). An electron microscopic study of clinical Paget's diseaese of the nipple. APMIS, 103, 628-34.

Karakas C (2011). Paget's disease of the breast. J Carcinog, 10, 100-108.

Kim HS, Moon HG, Han W, et al (2012). COX2 overexpression is a prognostic marker for Stage III breast cancer. Breast 
Cancer Res Treat, 132, 51-9.

Kirkina V, Joos S, Zo M (2004). The role of Bcl-2 family members in tumorigenesis. Biochim Biophys Acta, 1644, 229-49

Lester T, Wang J, Bourne P, et al (2009). Different Panels of Markers Should Be Used to Predict Mammary Paget's Disease Associated with In Situ or Invasive Ductal Carcinoma of the Breast. Ann Clinical Laboratory Science, 39, 17-24.

Li Xiang, Shiqi Wang, Xianqing Jin, et al (2012). Expression of BMP2, TLR3, TLR4 and COX2 in colorectal polyps, adenoma and adenocarcinoma. Molecular Medicine Reports, 6, 973-6.

Masferrer JL, Leahy KM, Koki AT, et al (2000). Antiangiogenic and antitumor activities of cyclooxygenase-2 inhibitors. Cancer Res, 60, 1306-11.

Meissner K, Rivière A, Haupt G, Löning T (1990). Study of Neuprotein expression in mammary Paget's disease with and without underlying breast carcinoma and in extramammary Paget's disease. Am J Pathol, 137, 1305-9.

Mohammad AM, Abdel HA, Abdel W et al (2006). Expression of cyclooxygenase-2 and 12-lipoxygenase in human breast cancer and their relationship with HER-2/neu and hormonal receptors: Impact on prognosis and therapy. Indian J Cancer, 43, 163-8.

Muir R (1939). Further observations on Paget's disease of the nipple and associated lesions. $J$ Pathol, 49, 299-312.

O'Byrne KJ, Dalgleish AG (2001). Chronic immune activation and inflammation as the cause of malignancy. Br J Cancer, 85, 473-483.

Ortiz-Pagan S, Cunto-Amesty G, Narayan S, et al (2011). Effect of Paget's disease on survival in breast cancer: an exploratory study. Arch Surg, 46, 1267-70.

Paget J (1874). On the disease of mammary areola preceding cancer of the mammary gland. St Bartholomews Hosp Rep, 10, 87-89.

Rhee J, Han SW, Oh DY, et al (2008). The clinicopathologic characteristics and prognostic significance of triplenegativity in node-negative breast cancer. BMC Cancer, $\mathbf{8}, 307$.

Rostamizadeh L, Fakhrjou A, Montazeri V, et al (2013) Bcl-2 gene expression in human breast cancers in Iran. Asian Pac J Cancer Prev, 14, 4209-14.

Sagami S (1963). Electron microscopic studies in Paget's disease. Med J Osaka Univ, 14, 173-88.

Silvestrini R, Veneroni S, Daidone MG, et al (1994). The Bcl-2 protein: a prognostic indicator strongly related to $\mathrm{p} 53$ protein in lymph node-negative breast cancer patients. J Natl Cancer Inst , 86, 499-504.

Smith WL, DeWitt DL, Garavito RM (2000). Cyclooxygenases: structural, cellular and molecular biology. Annu Rev Biochem, 69, 145-82.

Tawfik K, Kimler BF, Davis MK, Fan F, Tawfik O (2012). Prognostic significance of $\mathrm{Bcl}-2$ in invasive mammary carcinomas: a comparative clinicopathologic study between "triple-negative" and non-"triple-negative" tumors. Hum Pathol, 43, 23-30.

Yu B, Sun X, Shen HY, et al (2010). Expression of the apoptosisrelated genes BCL-2 and BAD in human breast carcinoma and their associated relationship with chemosensitivity. $J$ Exp Clin Cancer Res, 29, 107.

Zheng S, Song QK, Zhao L, et al. (2013) Characteristics of mammary Paget's disease in China: a national-wide multicenter retrospective study during 1999- 2008 . Asian Pac J Cancer Prev, 13, 1887-93.

Zhang GJ, Kimijima I, Abe R, et al (1997). Correlation between the expression of apoptosis-related bcl-2 and p53
DOI:http://dx.doi.org/10.7314/APJCP.2015.16.3.1041

COX-2 and Bcl-2 Overexpression in Paget's Disease of the Breast oncoproteins and the carcinogenesis and progression of breast carcinomas. Clin Cancer Res, 3, 2329-35.

Witton CJ, Hawe SJ, Cooke TG, Bartlett JM (2004). Cyclooxygenase -2 (COX-2) expression is associated with poor outcome in ER-negative, but not ER-positive , breast cancer. Histopathology, 45, 47-54. 